\title{
Biodiesel Production and Characterization from Used Vegetable Oil
}

\author{
*ODEGA, CA; ANGURUWA, GT; FAKOREDE, CO \\ Department of Forest Product Development and Utilization, Forestry Research Institute of Nigeria, Ibadan \\ *Corresponding Author Email: chiswart@gmail.com
}

\begin{abstract}
Biodiesel is a fuel produced from renewable resources; it is a clean alternative fuel, which has drawn the attention of energy researchers for the last two decades due to the disturbing effect of climate change caused by diesel fuel. This paper focuses on showcasing the qualities of biodiesel produced from used vegetable oil and the positive impact on the alarming change in climate today. This paper presents an experimental investigation on production of biodiesel from used vegetable oil (UVO) gotten from a road side bean cake (akara) seller. The oil that was intended to be thrown out was de-odoured and filtered to remove impurities. The filtered oil was then used for biodiesel production and characterized with physical and fuel properties such as density, viscosity, cloud point, refractive index, specific gravity, ash content, moisture content, flash point and cloud point. The results obtained were afterwards compared to ASTM (American Society for Testing and Materials) and EN (Europe's) international standards. Two biodiesels samples were produced at different temperatures but the same timings. The biodiesel were produced at $70^{\circ} \mathrm{C}$ at $40 \mathrm{mins}$ (biodiesel A) and $100^{\circ} \mathrm{C}$ at 40 mins (biodiesel B) with values of specific gravity $\left(0.98 \mathrm{~kg} / \mathrm{m}^{3} ; 0.90 \mathrm{~kg} / \mathrm{m}^{3}\right)$, density $\left(936 \mathrm{~kg} / \mathrm{m}^{3} ; 882 \mathrm{~kg} / \mathrm{m}^{3}\right)$, kinematic viscosity $\left(1.5 \mathrm{~mm} / \mathrm{s}^{2} ; 5.5 \mathrm{~mm} / \mathrm{s}^{2}\right)$, cloud point $\left(15^{\circ} \mathrm{C} ; 2^{\circ} \mathrm{C}\right)$, flash point $\left(260^{\circ} \mathrm{C} \mathrm{min} ; 200^{\circ} \mathrm{C} \mathrm{min}\right)$, moisture content $(0.07 \% ; 0.04 \%)$, refractive index $(1.4609 ; 1.4398)$ and ash point $(0.24 \% ; 0.01 \%)$ respectively. On comparison, biodiesel A couldn't match up to the international standards while biodiesel matched up to the standards given.
\end{abstract}

\section{DOI: $\underline{\text { https://dx.doi.org/10.4314/jasem.v25i4.7 }}$}

Copyright: Copyright $\left({ }_{0} 2021\right.$ Odega et al. This is an open access article distributed under the Creative Commons Attribution License (CCL), which permits unrestricted use, distribution, and reproduction in any medium, provided the original work is properly cited.

Dates: Received: 12 December 2020; Revised: 26 January 2021; Accepted: 12 February 2021

Keywords: Biodiesel, Used Vegetable Oil (UVO), Characterization, Viscosity

Energy is a fundamental requirement for human existence. Many countries in the world are resorting to biodiesel technology to solve the problem of the steady rising rate of fuel ensuing from the reduction of the world's non-renewable fossil fuels, and environmental pollution at large (Ibeto et al, 2011). This has led to the research into alternative fuels to replace conventional petroleum fuel of which biodiesel is one of them. Biodiesel is a renewable energy source which can be produced from vegetable oils and animal fats. Biodiesel as an alternative fuel has numerous advantages over conventional fossil fuels such as biodegrability, renewability, high combustion efficiency, low hydrocarbon and particulate matter (Sharma and Singh, 2009). It actually produces less particulate, having higher octane numbers and producing lower carbon monoxide and hydrocarbon emissions (El-Diwani et $a l, 2009)$. The utilization of biodiesel works by minimizing energy wear and tear; thereby increasing the service-life of the fuel injection equipment. It has also been made known by El-Diwani and El-Rafie, (2008) to possess a higher lubricity than any other fuels. Groundnut is mainly grown in the Northern part of Nigeria in large quantities. It has been reported that Nigeria possesses a land area of $923,768 \mathrm{~km}^{2}$ arable land constituting about 56\% of land mass and vegetation ranging from the Sahel savannah in the extreme North to swamp forest in the south (Sambo, 2007). Therefore, most parts of Nigeria are suitable for bio-fuel crop cultivation including groundnut oil (Ofoefule et al, 2008). Although the utilization of edible oil and food crops is capable of posing a threat to food security; the successful recovery of used vegetable oil for biodiesel production will eliminate this impending threat enabling used vegetable oil from restaurants, road-side sellers, food vendors and households be recycled into biodiesels. Biodiesels can be mixed with diesel without additive making it miscible. It is a cleaner source of fuel (Ibeto et al, 2011) and does not cause environmental pollution due to its reduced rate of lead, low sulphur and hydrocarbon gases which contributes greatly to cancer, respiratory problems and soot. The used vegetable oil (UVO) discarded from a restaurant is getting popular as feedstock for biodiesel fuel since several researchers has proposed that waste vegetable oil is best raw material for biodiesel production (Beatrice et al, 2014). The chemical reaction for the manufacturing of biodiesel using vegetable oil is the Transesterification reaction. Here, the fatty acids react with an alcohol (preferably methanol) in the presence 
of an alkali to produce an ester and glycerol. In some cases, saponification can occur as a side reaction in the presence of moisture and excess alcohol (Fukuda et al, 2001).

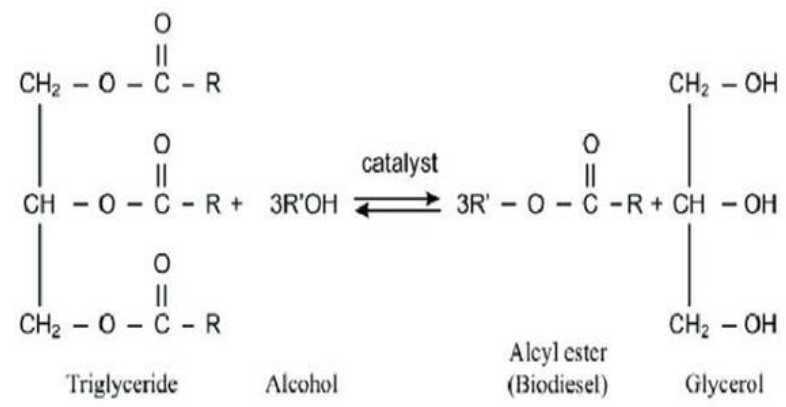

Fig 1: Transesterification of Biodiesel reaction (Biodiesel handbook, 2010)

This strategy is effectively being employed in USA and Brazil as they are world's largest producers of biodiesel (Ibeto et al., 2011). A good biodiesel has a pour point of $\geq 3^{\circ} \mathrm{c}$ (Peterson et al, 1990). It is often used to specify the cold temperature usability of fuel oil (Enciner et al, 2007). This study was carried out to assess the fuel quality of biodiesel which comprises of its production, characterization and modeling thereby bringing to light the conversion of used vegetable oil to biodiesel; a recyclable resource and wealth process. This waste to wealth process does not only generate revenue for any country but also solves issues posed by land, sea and air environmental pollution.

\section{MATERIALS AND METHODS}

Raw Materials: Analytical grade reagents; Methanol and Sodium hydroxide $(\mathrm{NaOH})$ were used for all the analysis carried out without further purification while the used vegetable oil was gotten from a bean cake (akara) seller located along Oria road, Delta State. The experiment was carried out at the laboratory of the Department of Pharmacy, Delta State University, Abraka, Nigeria

Method: In this study, production of biodiesel was done at different temperatures at the same timings and the same experimental analyses conducted on each of the biodiesel produced. These temperatures were rated at $70^{\circ} \mathrm{C}$ in 40 mins and the other at $100^{\circ} \mathrm{C}$ in 40 mins. This was done to determine the best temperature at which biodiesel can be produced. The oil collected was filtered into a clean bowl using a filter net, after which a little quantity of water was added to $3.5 \mathrm{~g}$ of Sodium hydroxide $(\mathrm{NaOH})$ pellets in order to reduce the concentration of $\mathrm{NaOH}$ pellets and the mixture was stirred. $150 \mathrm{ml}$ of methanol was poured into a round bottom flask, $150 \mathrm{ml}$ of the used vegetable oil was also poured into the round bottom flask containing the methanol and then the content was stirred. While stirring, the mixture containing the less concentrated $\mathrm{NaOH}$ was added.

Using the Sohxlet extraction setup as shown in Fig. 2 below, a reflux condenser was connected to the mouth of the round bottom flask containing the mixture while the set- up was placed on a heating mantle then one end of a pipe was connected to a running tap and the other end to the inlet of the reflux condenser. As another pipe was connected to the outlet of the reflux condenser the other end of the pipe was connected to an empty container. Ensuring a continuous flow of water from the tap to the inlet pipe (this was to ensure there was no outlet of vapor). The mixtures were heated simultaneously at different temperatures of $70^{\circ} \mathrm{C}$ and $100^{\circ} \mathrm{C}$ for 40 minutes. After 40 minutes, the mixture was allowed to cool before it was transferred into a separating funnel for 2 hrs until the biodiesel was separated from the glycerol which stayed at the bottom of the separating funnel as glycerol has higher density than the biodiesel.

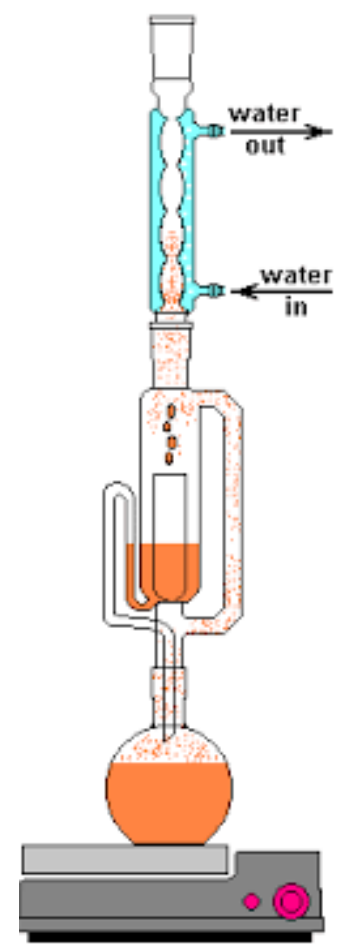

Fig. 2: Set-up of a Soxhlet extraction method (Wikipedia, 2019).

The glycerol which was at the base of the separating funnel was turned out into a beaker. The obtained biodiesel was then washed with warm water 5-6 times to a neutral $\mathrm{pH}$ to remove the remnants of glycerol, catalyst and other impurities following Alamu et al, (2007); further heating of the biodiesel in a beaker makes it more concentrated so it was heated until the strong smell of biodiesel was achieved. 
Determination of Refractive Index: Using a refractometer, the face on which the sample was placed was cleaned using cotton wool to avoid alteration of reading. Then using the stirrer, a drop of the sample was placed on the refractometer and the reading was taken.

Determination of Flash point: $2.5 \mathrm{ml}$ of the sample (biodiesel) was poured into a porcelain dish of a predetermined weight. The biodiesel sample was heated for some minutes and a piece of paper was lighted and was waved across the diesel being heated. The point at which the diesel became ignited was recorded as the flash point. When a flame was observed and the temperature was immediately recorded with the use of thermometer.

Determination of Ash point: The ash point was done alongside the flashpoint. The paper was lighted a second time and waved over the heating biodiesel until it lights up. The flame was left to burn till dryness. After the flames goes out, it was allowed to cool in a dessicator and the weight was measured. The ash point was then calculated using the formula;

$$
\text { Ash content }(\%)=\frac{\text { weight of ash }}{\text { weight of sample }} * 100
$$

Determination of Cloud point: $5 \mathrm{ml}$ of the sample was poured into a test tube, ice was scooped into a beaker and the test tube containing the sample was placed in the beaker containing the ice. It was observed until wax crystals were noticed at the surface of the sample after which the temperature was recorded at this point.

Determination of Moisture content: $4 \mathrm{ml}$ of the sample (biodiesel) was poured into the porcelain dish with a predetermined weight and was heated in the oven at $100^{\circ} \mathrm{C}$ for 1 hour. After the time elapsed, it was immediately weighed again to avoid absorption of moisture.

Determination of Specific gravity: Specific gravity also refers to relative density. It is simply the comparison of the mass of a fluid to that of water. $5 \mathrm{ml}$ of water was poured into a cylinder of a known weight; the cylinder with the water was then weighed and recorded. The final weight was subtracted from the initial weight (mass). The same procedure was repeated for the biodiesel and readings taken after which the formula was applied;

$$
\mathrm{S} . \mathrm{G}=\frac{\text { mass of sample }}{\text { mass of water }}
$$

Determination of Density: Density acts as a characteristic property of a substance. It is simply the relationship between the mass of the substance and how much space it takes up (volume). $5 \mathrm{ml}$ of the sample (biodiesel) was poured into a cylinder whose weight reading has been recorded. The cylinder with the biodiesel was weighed and recorded. The final weight was subtracted from the initial weight (mass). The formula was applied to get the density of the sample.

$$
\text { Density }=\frac{\text { mass }}{\text { volume }}
$$

Determination of Viscosity: $10 \mathrm{ml}$ of the sample (biodiesel) was poured into a beaker, viscometer spindle suitable for the quantity of biodiesel poured, was dipped into the sample until it covered a considerable amount of the spindle. The rotational rate was set at $30 \mathrm{rpm}$ for $5 \mathrm{mins}$, and the reading was taken.

\section{RESULTS AND DISCUSSION}

Different results were obtained as several tests of the characteristics of oil were carried out on them. Some were within limits when compared with ASTM (American Society for Testing and Materials) and EN (Europe) standard while others were not. Results in table 1 show the characterization carried out on the biodiesel produced at $70^{\circ} \mathrm{C}$ in 40 mins while table 2 shows the results of the characterization carried out on the biodiesel produced at $100^{\circ} \mathrm{c}$ in $40 \mathrm{mins}$.

Density: Generally, the density of petroleum products increases with molecular weight but increases with unsaturation level. High density of biodiesel or its blend can lead to incomplete combustion and particulate matter emissions (Galadinma et al, 2008). Biodiesel A $\left(70^{\circ} \mathrm{C}\right.$ at $\left.40 \mathrm{mins}\right)$ at $936 \mathrm{~kg} / \mathrm{m}^{3}$ had higher density than the biodiesel $\mathrm{B}\left(100^{\circ} \mathrm{C}\right.$ at $\left.40 \mathrm{mins}\right)$ at $882 \mathrm{~kg} / \mathrm{m}^{3}$. Biodiesel B density at $882 \mathrm{~kg} / \mathrm{m}^{3}$ falls in line with the EN standards at $860-900 \mathrm{~kg} / \mathrm{m}^{3}$ and aligns with the result gotten by Olusegun et al, (2019) which was at $883.63 \mathrm{~kg} / \mathrm{m}^{3}$ while Biodiesel A had a value of $936 \mathrm{~kg} / \mathrm{m}^{3}$ which is way higher implying that biodiesel B would leave little or no deposits in car engines. In comparison with the density of diesel which ranges from $820-860 \mathrm{~kg} / \mathrm{m}^{3}$ against EN standards and UVO biodiesel, biodiesel B is way better off and fits well into the standards given. Furthermore, Wahyuni et al, (2015) and Rusidianasari et al, (2020) in their work explained that the higher the reaction temperature used, the lower the density hence the decrease in densities of biodiesel A and B. This is because an increase in temperature would cause molecules to move faster creating room for collision and the more the collision, the more the conversion process. Also, Tat and Gerpen, (2000) also pointed out that the density variation would always influence the strength and quality of fuel burst during injection processes. 
Table 1: Characteristics of biodiesel produced at $70^{\circ} \mathrm{C}$ at $40 \mathrm{mins}$ (biodiesel A)

\begin{tabular}{llll}
\hline Characteristics & Biodiesel & ASTM & EN \\
\hline Specific gravity & 0.98 & $0.86-0.90$ & - \\
Kinematic viscosity $\left(\mathrm{mm} / \mathrm{s}^{2}\right)$ & 1.5 & $1.9-6.0$ & $3.5-6.0$ \\
Ash content $(\%)$ & 0.24 & 0.02 & 0.02 \\
Moisture content $(\%)$ & 0.07 & 0.05 & 0.05 \\
Refractive index at $24^{0} \mathrm{C}$ & 1.4609 & - & - \\
Flash point $\left({ }^{\circ} \mathrm{C}\right.$ min $)$ & 260 & 130 & 120 \\
Density $\left(\mathrm{kg} / \mathrm{m}^{3}\right)$ & 936 & - & $860-900$ \\
Cloud point $\left({ }^{\circ} \mathrm{C}\right)$ & 15 & - & - \\
\hline
\end{tabular}

Table 2: Characteristics of biodiesel produced at $100^{\circ} \mathrm{c}$ at $40 \mathrm{mins}$ (biodiesel B).

\begin{tabular}{llll}
\hline Characteristics & Biodiesel & ASTM & EN \\
\hline Specific gravity & 0.90 & $0.86-0.90$ & - \\
Kinematic viscosity $\left(\mathrm{mm} / \mathrm{s}^{2}\right)$ & 5.5 & $1.9-6.0$ & $3.5-6.0$ \\
Ash content $(\%)$ & 0.01 & 0.02 & 0.02 \\
Moisture content $(\%)$ & 0.04 & 0.05 & 0.05 \\
Refractive index at $24{ }^{0} \mathrm{C}$ & 1.4398 & - & - \\
Flash point $\left({ }^{\circ} \mathrm{C}\right.$ min $)$ & 200 & 130 & 120 \\
Density $\left(\mathrm{kg} / \mathrm{m}^{3}\right)$ & 882 & - & $860-900$ \\
Cloud point $\left({ }^{\circ} \mathrm{C}\right)$ & 2 & - & - \\
\hline
\end{tabular}

Specific gravity: the specific gravity of biodiesel is usually lower than that of water and since the fatty acid content always determine the specific gravity; the denser the vegetable oil, the denser the biodiesel. Additionally, the denser the biodiesel the higher the energy content thereby resulting in better mileage and increased strength. Biodiesel A at 0.98 was a bit higher than that of biodiesel B whose value read 0.90 thereby making biodiesel $\mathrm{B}$ within ASTM standard specification of $0.86-0.90$ and automatically more recommendable. Specific gravity is an important parameter for diesel fuel injection system. More reason why it must have tolerable limits (this is to allow optimal air to fuel ratios per complex combustions. However, biodiesel B with a value of 0.90 is in agreement with the result gotten by Younis et al. (2009) who in their work reported specific gravity of 0.904 .

Flash point: the flash point is the lowest temperature at which fuel produces enough vapor to cause an ignition which leads to flame. Biodiesel with higher flash points are less flammable or hazardous than biodiesels with lower flash points. The flash points for both biodiesel samples were well above the $130^{\circ} \mathrm{C}$ minimum ASTM recommended and therefore no risk of fire outbreaks in case of accidents. The results of the two biodiesel samples which were $260^{\circ} \mathrm{C}$ and $200^{\circ} \mathrm{C}$ were also greatly higher than that of Younis et al. (2009) and Olusegun et al. (2019) which was $80^{\circ} \mathrm{C}$ and $144^{\circ} \mathrm{C}$ respectively. The groundnut biodiesel is totally in contrast to the diesel fuel in terms of risk of fire outbreaks. The diesel fuel flash point of $>55^{\circ} \mathrm{C}$ may not be up to the international standards of $130^{\circ} \mathrm{C}$ or $120^{\circ} \mathrm{C}$ while the groundnut biodiesel $\mathrm{B}$ of $200^{\circ} \mathrm{C}$ is closer and way higher reducing the risk of possible fire outbreaks. The drastic reduction in the flash point values of biodiesel $\mathrm{A}$ and $\mathrm{B}$ is owing to the fact that biodiesel products with a low viscosity tend to have lower flash points (Rusidianasari et al. 2020). Moreover, the higher the flash point temperature, the lower the risk of possible fire outbreaks; this characteristic thereby poses a great merit for biodiesel over diesel fuels.

Ash content: this is done in order to check the noncombustible residue left after burning. Biodiesel A at $0.24 \%$ was way higher than the limits given by ASTM and EN standards at $0.02 \%$ unlike biodiesel B which was $0.01 \%$, lesser than the limit thereby assuring a lower deposit of carbon and an enhanced engine shelf life.

Cloud point: ASTM and EN did not specify the required cloud point for biodiesel probably due to the variance in climate condition worldwide, but requires that the cloud point be reported to the customer. If a customer is not careful to select an appropriate biodiesel feedstock, the fuel may get cloudy unexpectedly in cold weather and can block the fuel filters. The cloud point is usually used to test the performance of the biodiesel during unusual low temperatures. Olusegun et al. (2019) and Younis et al. (2009) in their respective studies got a cloud point of $7.3^{\circ} \mathrm{C}$ and $-2^{\circ} \mathrm{C}$ respectively which is quite different from the biodiesel results of $15^{\circ} \mathrm{C}$ and $2^{\circ} \mathrm{C}$ obtained in this study. However, it is important to note that the lower the cloud point, the better the biodiesel. Furthermore, considering the cloud point of diesel fuels which is between $-9^{\circ} \mathrm{C}$ and $-16^{\circ} \mathrm{C}$, the biodiesel $\mathrm{B}$ value of $2^{\circ} \mathrm{C}$ and that of Younis et al. (2019) of $-2^{\circ} \mathrm{C}$ can be used as perfect blends for diesel fuels due to their higher temperature.

Kinematic viscosity: this property is usually done to know the flow property of the biodiesel. The biodiesel 
A turned out to be $1.5 \mathrm{~mm} / \mathrm{s}^{2}$ which is lower than the ASTM $\left(1.9-6.05 \mathrm{~mm} / \mathrm{s}^{2}\right)$ and EN $\left(3.5-6.05 \mathrm{~mm} / \mathrm{s}^{2}\right)$ standards while biodiesel B which is $5.5 \mathrm{~mm} / \mathrm{s}^{2}$ remains within the limit of both standards. While evaluating the conventional diesel values (2.5$3.5 \mathrm{~mm} / \mathrm{s}^{2}$ ) to the UVO biodiesel produced, it is observed that while biodiesel $\mathrm{A}\left(1.5 \mathrm{~mm} / \mathrm{s}^{2}\right)$ was way lower than the conventional diesel values, biodiesel $\mathrm{B}$ surpass its values and fitted better into the international standards given. It was also reported by Rusidianasari et al. (2020) that the viscosity of the biodiesel yield will increase with a higher temperature. With an increase in temperature, there is an increase in the conversion of triglycerides thereby increasing the flow property of the product. Wahyuni et al. (2015) also found out that the higher the viscosity, the thicker and more difficult for the biodiesel to flow. It is also important to note that biodiesel with high viscosity usually results in an improper atomization of the fuel injector. It could also form large droplets on injection resulting in exhaust smokes and poor combustion. This contributes greatly to air pollution and several air causative diseases. On the other hand, diesel fuels with low viscosity usually possess low lubrication in the injection pumps leading to increased wear.

Refractive index: many materials have a well characterized refractive index but these indices depend strongly on the frequency of light. The Refractive Index is a useful property for the standardization of the product and it also reveal the state of the biodiesel. For example, at the cloud point of the biodiesel, a cloudy state appears and the refractive Index changes. Though refractive index standard has not been given by ASTM standard, biodiesel A and B both had values of 1.4609 and 1.4398 at $24^{\circ} \mathrm{C}$ respectively which were slightly different from value gotten by Irina et al, (2013) whose value was 1.4548 at $25^{\circ} \mathrm{c}$.

Moisture content: this is done in order to check for the amount of moisture present in the biodiesel produced. Biodiesel A produced a higher moisture content of $0.07 \%$ which was higher than the ASTM and EN standard given while the biodiesel B sample was $0.04 \%$ which is within limit because it was boiled at a higher temperature. High moisture content in biodiesel could cause water accumulation thereby leading to microbial growth during storage and rusting of transportation equipment. However, this could still occur during the production process by the absorption of moisture if not properly kept (Van Gerpen, 2005).

Conclusion: Running by the progress of this study, Biodiesel $\mathrm{B}$ was better than biodiesel A proving that boiling at higher temperature will usually yield better biodiesel quality. Boiling at a higher temperature speeds up methanol dissolution and fastens the reaction thereby given off more vapor pressure. There is also a distinctive difference in the parameter results of Biodiesel A and B which is mainly due to the increase in reaction temperature of the production. This study remains relevant due to the decrease in oil reserves, environmental problems and the high price of petroleum products in the international market.

\section{REFERENCES}

Alamu, OJ, Waheed, M. Ajekayinfa, SO; Akintola TA. (2007). Optimal transesterification duration for biodiesel production from Nigerian palm kernel oil. Agric. Eng. Int. the CIGRE-J. 9. 1-11.

American Society for Testing and Materials (2002). Standard specialization for biodiesel fuel (b100) Blend stock for distillate fuel, Designation D675102, ASTM International, West Conshohocken, PA.

Beatrice, OO, Onyia, OC, Abdulraman, FW. (2014). Production of biodiesel from used vegetable oil. GIFRE. 3(1):274-277.

Biodiesel Production in the Biodiesel Handbook, $2^{\text {nd }}$ Edition (2010). pp: 31-65

El-Diwani, G, Attia. NK; Hawash, SI. (2009). Development and evaluation of biodiesel fuel and by-products from jatropha oil. Int. J. Environ. Sci. Tech, 6:219-224.

El-Diwani, G. and El-Rafie, S. (2008). Modification of thermal and oxidative properties of biodiesel oil produced from vegetable oils. Int. J. Environ. Sci. Tech. 5:391-400.

Encinar, JM., Cronzales, JF, Rondriguez-Reinares, A. (2007). Ethanolysis of used frying oil biodiesel preparation and characterization. FPT, 88:513522.

Fukuda, HA, Noda, H. (2001). Biodiesel fuel production by Transesterification of oils. $J$. Bioengineer. 92(5):405-416.

Galadima, A, Garba, Z. and Ibrahim, BM. (2008). Homogenous and heterognous transesterification of groundnut oil for synthesizing methyl biodiesel. Int J Pure App Sci, 2:138-144.

Ibeto, CN, Ofoefule, AU; Ezugwu, HC. (2011). Analytical Methods for Quality Assessment of Biodiesel from Animal and Vegetable Oils. Trends Applied Sci. Res, 6:537-553. 
Irina, N, Sibei G, Anisoara, N, Elis, G. (2013) Estimation of the refractive Index of diesel fuel + biodiesel blends. Ovidus Uni. Annals of Chem. 24.24-26

Ofoefule, AU, Uzodinma, EO, Ukoha, PO, Okoro, UC; Onukwuli, OD. (2008). Biofuels potential in Nigeria and the future of petroleum. Nig. J. Solar Energy. 19:73-77.

Olusegun, DS, Benjamin, UO, Oluwayomi, JO, Stanley, I. and Ojo, SI. (2019). Experimental and empirical study of diesel and biodiesel produced from blend of fresh and waste vegetable oil on density, viscosity, sulphur content and acid value. $J$ Phys Conf Ser. Doi:10.1088/17426596/1378/4/042024.

Peterson, CL, Cruz, R, Perkings, L, Konis, R. and Auld, D.L. (1990). Transesterification of vegetable oil for use as diesel fuel: a progress report. ASAE paper No. 90-610.

Rusidianasari, R, Bow, Y, Moulita, R. (2020). Temperature effect on the biodiesel quality from waste cooking oil by induction heating. J. Phys. Conf. Ser. Doi: 10.1088/17426596/1450/1/012003.

Sharma, YC, Singh, B. (2009) Development of biodiesel: current scenario. Renew Sust. Energ. Rev. 13:1646-1651

Sambo, AS, (2007). Renewable energy development in Nigeria: A situation report. Proceedings of the international workshop on renewable energy development in Africa, July 30-Aug. 1, University of Nigeria, Nsukka, pp: 1-39.
Tat, ME, Van Gerpen, JH, (2000). The Specific Gravity of Biodiesel and its blends with Diesel fuel. J.Am. Oil Chem. Soc77. 115-119

US Department of Energy, (2004). Biodiesel; handling and use guidelines. Energy efficiency and use guidelines. Energy efficiency and renewable energy, United States Department of Energy.

Van Gerpen, J, (2005). Biodiesel processing and production. Fuel Process Tech. 86: 1097-107.

Wahyuni, S et al. (2015). The effect of Process temperature and Deposition Time on the quality of Biodiesel from used cooking oil. J. Pillar. Phys. 6; 33-40

Younis, MN; Saeed, MS; Khan, S; Furqan, MU; Khan RU; Saleem, M (2009). Production and Characterization of Biodiesel from Waste and Vegetable Oils. J Oual. Tech Manage. 5 (1). 111121.

Zhang, S; Zu, YG; Fu, YJ; Luo, M; Zhang DY; Efferth T (2010). Rapid microwave -assisted tranesterification of yellow horn corn oil to biodiesel using a heteropolyacid solid catalyst. Biores. Technol. 101(3) 931-936. 